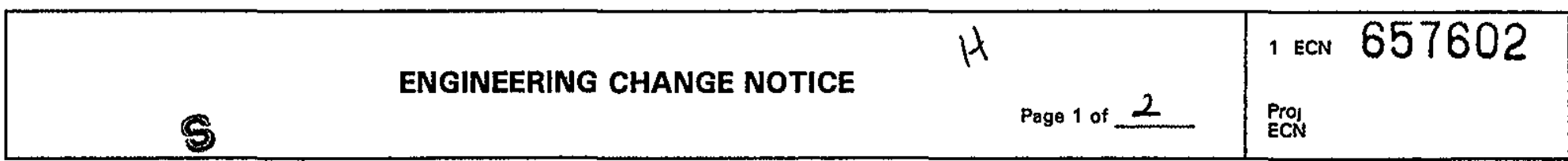

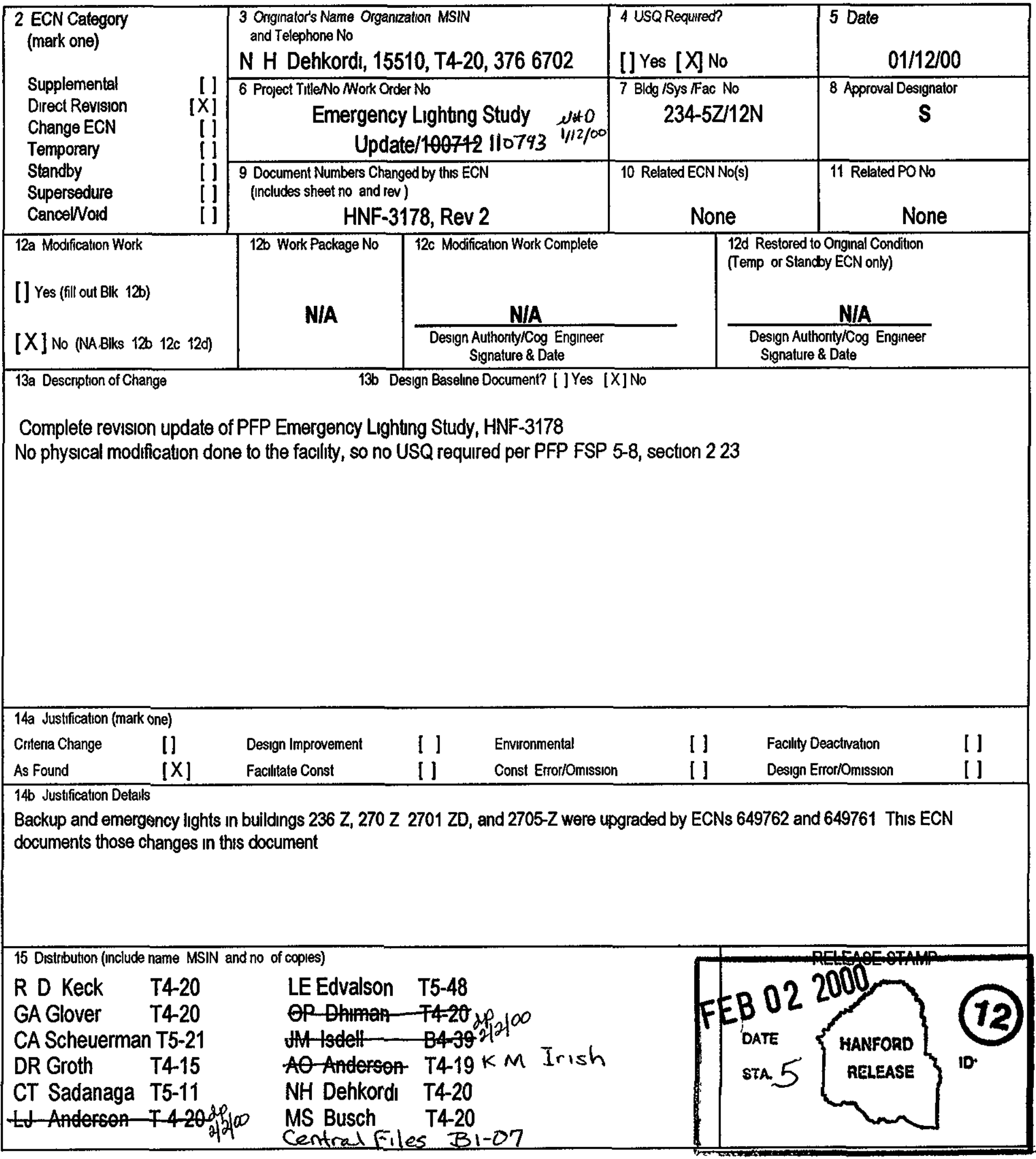




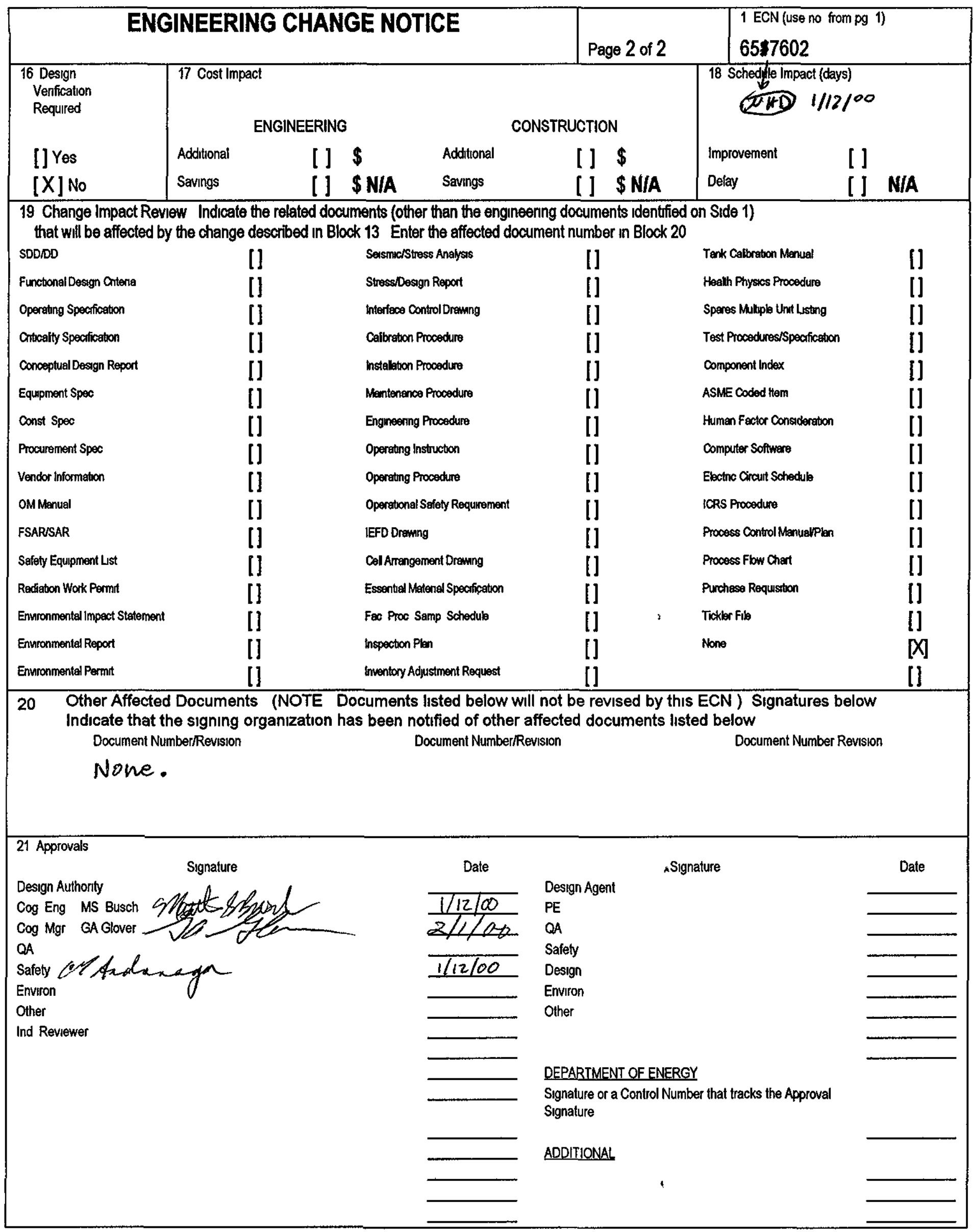


9

\section{PFP EMERGENCY LIGHTING STUDY}

\section{S Busch}

B\&W Hanford Company, Richland, WA 99352

U S Department of Energy Contract DE-AC06-96RL13200

$\begin{array}{llll}\text { EDT/ECN } & 657602 & \text { UC } & 506 \\ \text { Org Code } & 15510 & \text { CACN } & 110793 \\ \text { B\&R Code } & \text { EW7002000 } & \text { Total Pages } & 31\end{array}$

Key Words PFP Emergency Lights, Backup Lights

Abstract This engineerng study documents PFP's current emergency light configuration and light levels, identfies deficiencies in the emergency lightng system and proposes lighting upgrades to more closely comply with NFPA 101 Section 59 requirements

TRADEMARK DISCLAIMER Reference heren to any specric commercial product process or service by trade name trademark manufacturer or otherwnse does not necessanly consttute or imply its endorsement recommendation or favoring by the United States Government or any agency thereof or its contractors or subcontractors

Printed in the United States of Amenca To obtain copies of this document, contact Document Control Services PO Box 950 Malstop H6-08 Richland WA 99352 Phone (509) 3722420 Fax (509) 376-4989
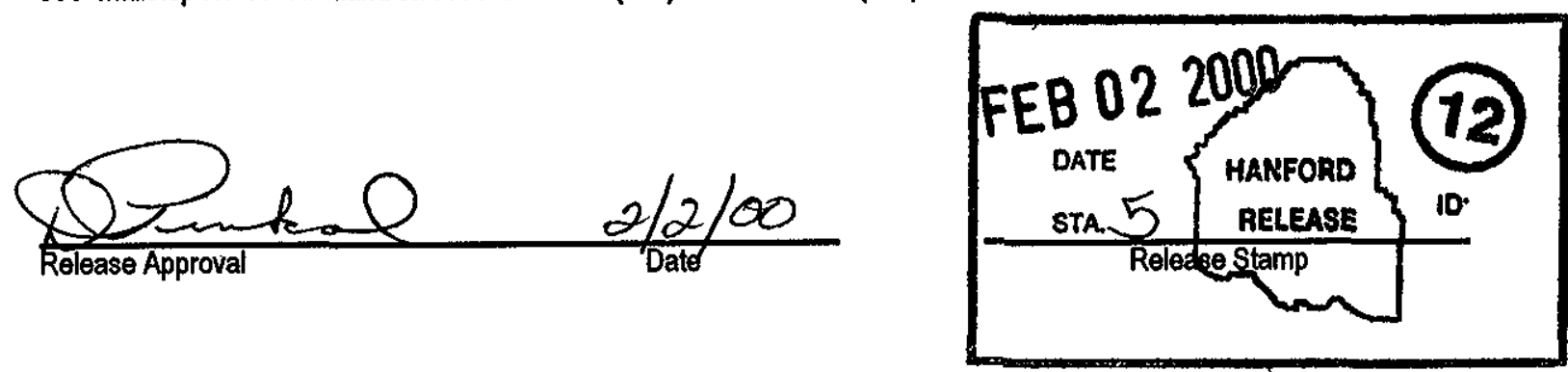

\section{Approved for Public Release}




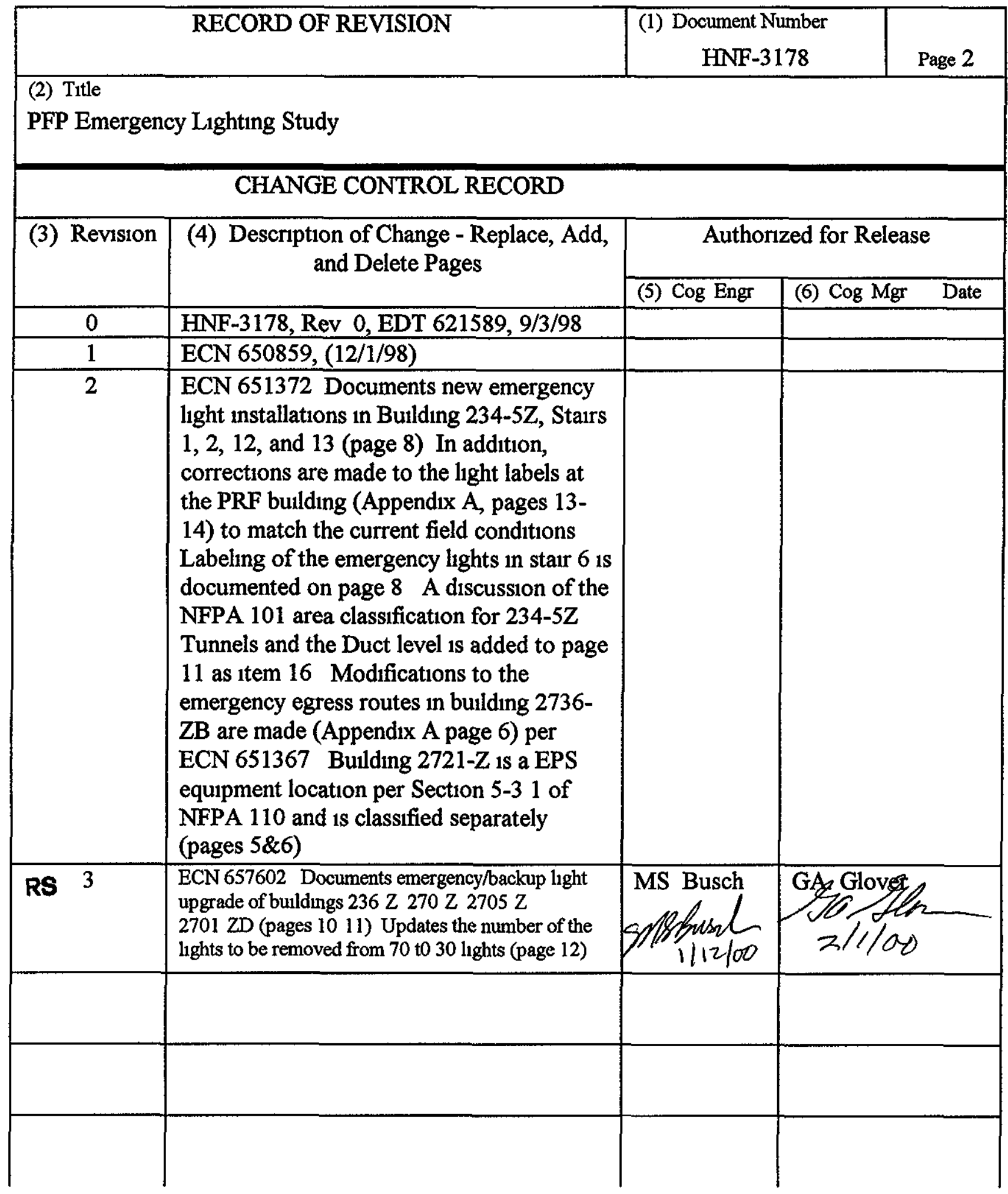




\section{OBJECTIVE}

\section{BACKGROUND AND SCOPE}

NFPA 101, section 5-9 mandates that, where required by building classification, all designated emergency egress routes be provided with adequate emergency lighting in the event of a normal lighting outage Emergency lighting is to be arranged so that egress routes are illuminated to an average of 10 footcandle with a minimum at any point of 01 footcandle, as measured at floor level These levels are permitted to drop to $60 \%$ of their onginal value over the required 90 minute emergency lighting duration after a power outage

The Plutonium Finishing Plant (PFP) has two designations for battery powered egress lights "Emergency Lights" are those battery powered lights required by NFPA 101 to provide lighting along officially designated egress routes in those buildings meeting the correct occupancy requirements Emergency Lights are maintained on a monthly basis by procedure ZSR-12N-001 "Backup Lights" are battery powered lights not required by NFPA, but installed in areas where additional light may be needed The Backup Light locations were identified by PFP Safety and Engineering based on several factors

1 General occupancy and type of work in the area Areas occupied briefly during a shiftly survellance do not require backup lighting while a room occupied farly frequently or for significant lengths of time will need one or two Backup Lights to provide general illumination of the egress points

2 Complexity of the egress routes Office spaces with a standard hallway/room configuration will not require Backup Lights while a large room with several subdivisions or irregularly placed rooms, doors, and equipment will require Backup Lights to make egress safer

3 Reasonable balance between the safety benefits of additional lighting and the manhours/exposure required for periodic light maintenance In some plant areas such as bulding 236-Z, the additional maintenance time and risk of contamination do not warrant having Backup Lights installed in all rooms Sufficient light for egress is provided by exısting lights located in the hallways

Backup Lights are not subject to the same light intensity requirements as Emergency Lights and are maintained on a quarterly basis by procedure ZSR-12N-002 The reduced maintenance for Backup Lights ensures light operability whle allowing significant manpower savings and application of ALARA principles Battery powered lights not designated as Emergency or Backup Lights are not required and will be removed from the facility and the maintenance procedures 
PFP has buildings with three different NFPA occupancy classifications, Business Use, Industrial Use (both General and Special Purpose), and Storage Use Additionally, several buildings are Mixed Use facilities with both Business and Industrial uses The buildings' classification and frequency of habitation determine the need for emergency lighting as follows

According to section 27-2 91, buildings classified as "Business Use" are required to maintain an emergency light system if one of the following is true

(1) The building is two or more stories in height above the level of exit discharge, or

(2) The occupancy is subject to 100 or more occupants above or below the level of exit discharge, or

(3) The occupancy is subject to 1,000 or more total occupants

Section 28-2 91 requires buildings classified as "Industral Use" to maintain an emergency light system unless one of the following Exceptions are met

Exception No 1 Special Purpose Industral occupancies where routine human habitation is not the case

Exception No 2 Structures occupıed only during daylight hours with skylights or windows arranged to provide the required level of llimination on all portions of the means of egress during these hours

Section 29-2 91 requires buildings classified as "Storage Use" to maintain an emergency light system unless one of the following Exceptions are met

Exception No 1 Storage occupancies do not require emergency lighting when not normally occupied

Exception No 2 Structures occupied only during daylight hours with skylights or windows arranged to provide the required level of illumination on all portions of the means of egress during these hours

PFP Safety has classtfied the plant buldings per NFPA occupancy requirements as follows

Building 234-5Z Complex (First \& Second Floor)

Classification Mixed use, Business and Industral, both General and Special Purpose

Requirements Emergency lightıng is required along egress routes Areas along egress routes with very low lighting levels will be upgraded Designated Backup Lights will remain in some additional areas The remaining battery powered lights will be removed

Building 234-5Z Complex (Duct Level \& Tunnels)

Classification Industral, Special Purpose

Requirements These areas are not routınely occupied Under Section 28-2 9 1, Exception No 1, they do not require emergency lighting Existing lights in these areas will be maintained as backup lights 


\section{Building 236-Z}

Classification Industrial, both General and Special Purpose

Requirements Under Section 28-2 91 Exception No 1, Bulding 236-Z is not routinely occupied so emergency lighting is not required Backup Lights will be maintained in the corndors while lights in individual rooms will be removed

\section{Bulding 2736-ZB}

Classification Business and Industral, both General and Special Purpose

Requirements Emergency lighting is required The power source of existing Emergency and Backup Lights will be changed to the local lighting circuit to ensure proper lighting levels in the event of a loss of only normal lightıng power

\section{Building 2736-Z}

Classification Storage

Requirements Emergency lighting is required Battery powered lights located in the individual vaults will be removed as they are not on the bulding egress route

\section{Building 2736-ZA}

Classification Industrial, Special Purpose

Requirements Under Section 28-2 91 Exception No 1, Building 2736-ZA is not routınely occupied so does not require emergency lighting

\section{Bulding 291-Z}

Classification Industrial, Special Purpose

Requirements Under Section 28-2 91 Exception No 1, Buldıng 291-Z is not routinely occupied so does not require emergency lighting Several Backup Lights will be installed to provide safer building egress

\section{Buildings 232-Z, 241-Z, 242-Z, 243-Z, and Z9 Crib}

Classification Industrial, Special Purpose

Requirements These buildings are not routinely occupied Under Section 28-2 91

Exception No 1 they do not require emergency lighting A few lights in these buildings will be left in place as Backup Lights while the remainder will be removed

\section{Building 2721-Z}

Classification Industrial, Special Purpose

Requirements This bulding is not routinely occupied Under Section 28-2 91 Exception No 1 it does not require emergency lighting However, Section 5-3 1 of NFPA 110 classifies this building as an Emergency Power System (EPS) Equipment Location and requires for this type of location to be provided with battery powered emergency lighting 
Therefore, the 2 lights in this location will be kept in place

Buildings 270-Z, 2701-ZA, 2701-ZD, 2704-Z, 2705-Z, and all trailers

Classification Business (these buildings are the Badgehouse, AMS, OCF, Admin, etc )

Requirements All of these buildings are single story with fewer than 1,000 occupants so they do not require emergency lightıng per section 27-2 91 Some lights in several of these buildings will be left in place as Backup Lights while the remainder will be removed

The above occupancy designations determine which buldings require emergency lighting as defined by section 5-9 of NFPA 101 Backup Lights installed in other areas are not subject to the light level and maintenance requirements associated with the NFPA

\section{SUMMARY}

This study establishes the baseline data from which improvements to the plant's emergency lighting system will be made These improvements are designed to provide emergency egress routes that are adequately lighted by Emergency Lights in all PFP buildings required by NFPA 101 In support of this goal, a plant-wide emergency escape light level survey was performed under Work Package 2Z-95-959 The survey documented numerous plant emergency lightıng deficiencies including low light levels, missing or relocated lights, and lights powered by the incorrect normal lighting circuit These light level measurements and deficiencies are shown in Appendix A Correction of these deficiencies will need to address several considerations

1 Drawing changes to cover the updated emergency light configuration and resolution of the existing out-of-date emergency lighting drawings

2 Prioritized resolution of the light level deficiencies identified by WP 2Z-95-959

3 Resolution of all wiring and labeling discrepancies

4 Removal of the lights not designated as Emergency or Backup Lights

5 Correction of power source problems identified in WP 2Z-95-959

6 Verification of maintenance procedure and drawing consistency in designation of Emergency and Backup Lights

\section{RECOMMENDATIONS}

\section{DRAWING CHANGES}

Currently, Emergency Lights are included on the buildings' general lightıng drawings These nonessential drawings do not reflect recent changes in the emergency light configuration It is necessary to keep the emergency light configuration up to date to ensure compliance with NFPA requirements and complete coverage of Emergency Lights by the appropnate ZSR procedures This will be accomplished by the development of a new essential drawing showing the location, 
power source, and number of each Emergency or Backup Light superimposed on the building egress routes A bulding layout format similar to the Room and Door Numbers drawing (H-280249) is well suted to this application

A note will be added to the existing general lighting drawings referring to the new essential drawings for all emergency lighting information New general lighting drawings will not be issued

\section{WORK PACKAGE 2Z-95-959 LIGHT LEVEL DEFICIENCIES}

Based on the emergency light survey results of Work Package 2Z-95-959, a prioritized list of areas needing additional lights to meet minimum NFPA requirements was developed The general pronties were

1 Emergency egress routes with inadequate light levels

2 Areas with Backup Lights that have power source problems or lights to be removed

3 Areas only requiring removal of existing lights

During the light level measurements of Work Package 2Z-95-959, the majority of the egress routes in buildings $234-5 \mathrm{Z}$ and $2736-\mathrm{ZB}$ fell below the average light level requirement of 10 footcandle but not below the 01 footcandle minimum The average emergency light level for these egress routes was approximately 05 footcandle Due to the limited life expectancy of the faclity and the fact that there are no areas below 01 footcandle along these egress routes, these particular areas will not be upgraded All issues such as incorrect power sources or labeling errors will still be fixed Egress routes in buildings 234-5Z and 2736-ZB with areas below the 01 footcandle minımum will be fully upgraded to NFPA requirements

The facility was divided into 20 groups (A through T) based on degree of upgrade required, radiological boundaries, and maintaining a manageable scope of work for an individual work package Appendxx A shows each group's boundaries and required improvements The groups were prontized as follows

\section{Group I Bulding 234-5Z, Second floor, Room 321}

This area had no emergency hight coverage and was completely dark during a normal lighting outage Room 321 provides the only egress for the Control Room, which is manned 24 hours per day, 7 days a week No other area had this high of an occupancy with such low emergency light levels Additionally, Room 321 contains many safety hazards, including rotatıng machınery, bump and trip hazards, and a non-standard room configuration with smaller adjoining rooms and offices 
As shown in Appendix A, 10 Emergency Lights were added along the egress routes in this room under work package 97-1694 Light levels along the egress routes now measure about 05 footcandles No further upgrades will be made to this room The west roof emergency lighting was previously upgraded under Work Package 2Z-96-2410 to provide lighting from the Room 321 exit onto the west roof to the two ladders down the south walls

2 Group D Building 234-5Z, First floor, Southwest corner (Lab Annex)

These corndors provide access to the three main exterior exits from the southwest corner of the building Although this area is a farly standard office configuration, it had no emergency lighting at the time of the survey As such, it was listed as prionty two

These corridors were upgraded with 11 new lights installed as shown in Appendix A under Work Package 2Z-97-1992 All light levels now meet or exceed the NFPA requirements

3 Group J Building 234-5Z, Stairs 1, 2, 6, 12, and 13

The stairs in building 234-5Z did not meet the NFPA requirements Most had areas of low light levels, and some had flights with no emergency light coverage These deficiencies represented significant trip and fall hazards during a lighting outage, especially during a building evacuation The stairs are the only emergency egress routes avallable from the second floor and duct level Since most starrs had at least some levels of emergency lighting, they were assigned a priority of three

As shown in appendix A, 16 additional lights were installed in starrs under Work Package 2Z-98-1374 to raise the stair emergency light levels to NFPA requirements The lighting level average for all the starrs now meet or exceed the NFPA requirements Stair 6 was upgraded under a previous package and did not require any additional lighting

4 Group C Bulding 234-5Z, First floor, RADTU area

The egress routes in this backside area provide two of the three exterior exits for the northwest part of the bulding through large open areas with non-standard room and hallway configurations This RADTU area has numerous areas well below the 10 footcandle average requirement coupled with several dark spots also below the 01 footcandle minimum Due to the level of existing emergency light coverage and the absence of the trip and fall hazards associated with stairs, this area was placed fourth on the priontized list 
Upgrading the emergency lighting will require 5 additional lights as shown in Appendix A There are also 3 lights to be removed and $1 \mathrm{light}$ on an incorrect power source

5 Group E Building 234-5Z, Backside RMA/RMC areas

Due to the complex layout of the RMA/RMC rooms and the industrial nature of the equipment, this area will be upgraded to meet the NFPA requirements Since there are no dark areas below the 01 footcandle minimum, this area was placed below the other areas receiving new light installations Nine new lights will be installed as shown in Appendix A There is one light to be removed from this area

6 Group O Buldings 2736-Z and 2736-ZB

Although these buldings already have installed Emergency Lights, the lights are connected to the emergency lighting panels instead of the normal lighting panels All lights in these buildings will be rewired to the normal lighting circuit in that area Since the existing lights will illuminate if power is lost to the emergency panels and the existing light levels are approximately 05 footcandle average, this group was placed sixth on the priority list

One new Emergency Light will be added as shown in Appendix A to correct a low intensity area in the entry corndor For the remainder of the bulding, even though the current light levels do not quite meet the NFPA requirements, new Emergency Lights will not be added due to the reasonable existing coverage Two Backup Lights will be added to the change room exits for added personnel safety during normal egress during a lighting outage The 8 lights in the 2736- $Z$ and $Z B$ vaults will be removed since the vault doors remain open if people are inside In an egress situation, illumination will be provided from the corridor Emergency Lights This represents a significant exposure and manhour reduction

7 Groups G \& H Bulding 234-5Z, Second floor frontside offices

This is a standard hallway/office area with a few dark spots along the egress route These low intensity spots below the 01 footcandle minimum will be upgraded with 3 additional lights as shown in Appendix A The remainder of the egress routes will not be upgraded as explained above due to the limited life expectancy of the facility and the existing light levels There are 2 lights to be removed and 2 lights with incorrect power sources

8 Group A Bulding 234-5Z, First floor frontside offices and change room addition 
As in Groups $\mathrm{G} \& \mathrm{H}$ above, only the areas below 01 footcandle will be upgraded This will require one light positioned as shown in Appendix A Additionally, 13 lights will be removed, 6 lights have incorrect power sources, and 2 lights require relabeling

9 Group B Building 234-5Z, First floor maintenance areas

No upgrade will be made to this group since there are no areas below the 01 footcandle minimum There is, however, one light to be removed and one light on an incorrect power source

10 Group N Building 291-Z

Due to the industrial nature of the building and lack of natural light, approximately 7 Backup Lights will be installed as shown in Appendix A As Backup Lights, they are not required by NFPA, and will be placed on the quarterly maintenance cycle This is the highest non-egress route priority

11 Group R Bulding 234-5Z Mezzanine

The Mezzanine level does not contain any designated emergency egress routes, so all battery powered lights in that area are Backup Lights Additionally, 6 lights are slated for removal and 2 lights are powered from the incorrect lighting circuit The lights remaining on the Mezzanine will provide adequate light for normal exit paths from that area The area will also receive a farr amount of background lightıng from the first floor lights in those rooms

\section{Groups K \& L PRF}

As a Special Purpose Industrial Occupancy, PRF falls under Exception No 1 for nonroutine habitation and does not require any emergency lighting As a prudent safety measure, the existing lights in the corndors remained as Backup Lights to provide coverage during a normal highting outage As shown on Appendix A, all other lights in mantenance shop, the control room, glovebox or filter rooms, etc (24 total) were removed This saved a great deal of maintenance time while still maintaining safely lit exits for the building

13 Group M Bulding 243-Z

As a Special Purpose Industrial Occupancy, building 243-Z falls under Exception No 1 for non-routtne habitation and does not require any emergency lighting There are 6 lights 
currently located in $243-Z$ Two of these existing lights will be removed and the remainder classified as Backup Lights

14 Group P Buldıngs 270-Z, 2701-ZD, and 2705-Z

These buildings are all Business Occupancies without requirements for any emergency lighting The existing lights in 2705-Z remained as Backup Lights due to the large number of personnel transiting that building As shown in Appendix A, three of the 7 lights in 2701-ZD were removed, leaving four Backup Lights in Patrol's high occupancy and transit areas The existing lights in $270-Z$ are connected to a different transformer from the normal lighting power After companing the benefit of keeping those lights in service to the cost of regular maintenance and relocating all of their power sources, and considering that $270-\mathrm{Z}$ is a building with substantial natural light and very simple corridors and floor plans Therefore, all the lights were removed from the bulding The changes are shown in Appendix A

15 Group S Bulding 216-Z9 (The Z9 Crib)

As a Special Purpose Industral Occupancy, the Z9 Crib falls under Exception No 1 for non-routme habitation and does not require any emergency lighting All battery powered lights will be removed from this bulding Group $S$ is not shown in Appendix A

16 Group T Building 234-5Z (Duct Level and the Tunnels)

As Special Purpose Industrial Occupancies, the Duct Level and the Tunnels (basement) in Building 234-5Z fall under Exception No 1 for non-routine habitation and do not require any emergency lighting The existıng Backup Lights in these areas will contınue to be maintained Group $\mathrm{T}$ is not shown in Appendix A

17 Groups F and Q (234-5Z, SE corner by HPT office, and 241-Z complex)

No changes are necessary for these areas Some of the SE corridor areas of 234-5Z do not fully meet the NFPA requirements but, as discussed previously, there are no low light intensity areas below the 01 footcandle minimum, so no additional Emergency Lights will be added The existing Emergency and Backup Lights in these areas will continue to be maintained

\section{WIRING AND LABELING DISCREPANCIES}


Numerous problems were found with the battery powered lights during the lighting survey, including

1 Lights powered by different sources than the local general lighting This results in Emergency Lights that remain on charge when the local lights go out, but turn on when the lights in a different room or corridor lose power

2 Lights that have been moved or deleted and have not been updated on the general lighting drawings This will be corrected by the drawing changes in section 21

3 Improperly labeled lights Several duplicate light numbers exist which cause confusion when comparing the Emergency and Backup Light lists These lights must be relabeled Additionally, proor to development of the new Emergency/Backup Light drawing, all battery powered lights will be relabeled to differentiate between Emergency and Backup Lights

These discrepancies will be corrected during the performance of the work packages for each of the 19 areas described in section 22

\section{LIGHT REMOVAL}

Currently, there are approxumately 30 lights that are not required for emergency or backup lighting and should be removed Removing these lights from service represents a significant savings in both personnel exposure and maintenance resources After removal, these lights may then be installed in those areas noted in section 22 as requiring additional emergency or backup lightıng Light removal will be accomplished by the same work packages as the light additions and deficiency corrections

\section{LIGHT DESIGNATION}

The two maintenance procedures, ZSR-12N-001 and -002, must be compared with the new drawings, lists of Emergency and Backup Lights, and actual field conditions to ensure complete and accurate maintenance coverage of all lights

\section{CONCLUSIONS}

As described above, there are several improvements to the emergency lighting system that are required to meet the NFPA 101 requirements and ensure that future changes are incorporated into the system drawings The proposed plan represents a balance of plant safety improvements in the form of light upgrades, man-hour savings through maintenance reduction, and ALARA considerations by removing lights not required in contamination or radiation areas The actual 
lighting upgrade will be accomplished by several work packages, each one covering an area of different priority The other concerns, such as power source and labeling changes, will also be addressed in these work packages Additionally, updates will be made to the emergency lighting and egress route drawings and the monthly/quarterly maintenance procedures These changes encompass a significant amount of work and reorganization of the emergency lightıng system, but are necessary to ensure compliance with NFPA regulations and personnel safety

\section{REFERENCES}
A NFPA 101
B Work Package 2Z-95-959
C Work Package 2Z-96-2410
D Work Package 2Z-97-1992
E Procedure ZSR-12N-001, "Emergency Lights Monthly Inspection and Annual Testıng"
F Procedure ZSR-12N-002, "Backup Lights Quarterly Inspection and Biannual Testing"

\section{APPENDIXES}

A Groups A through R Plant Sketches 


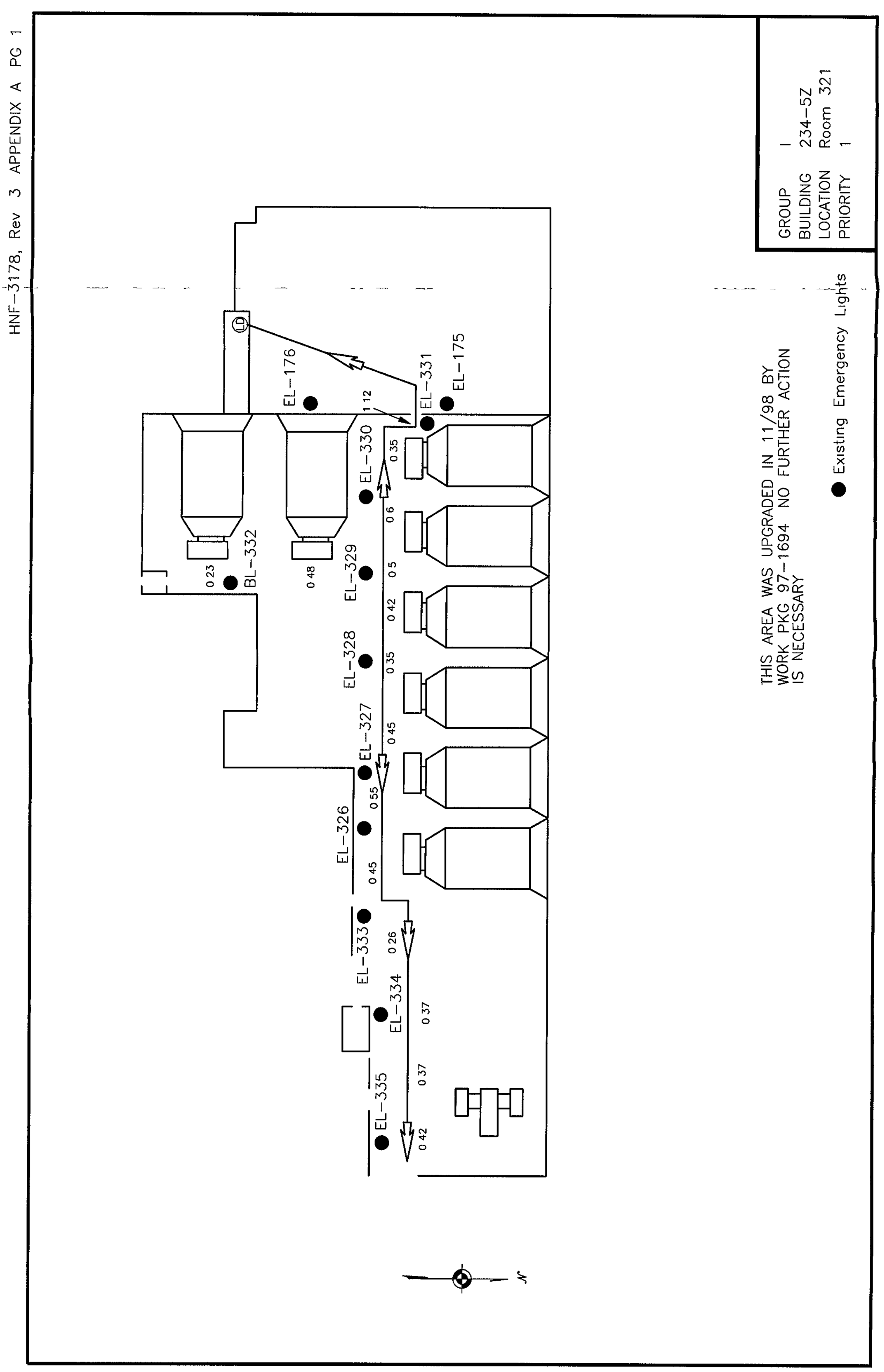




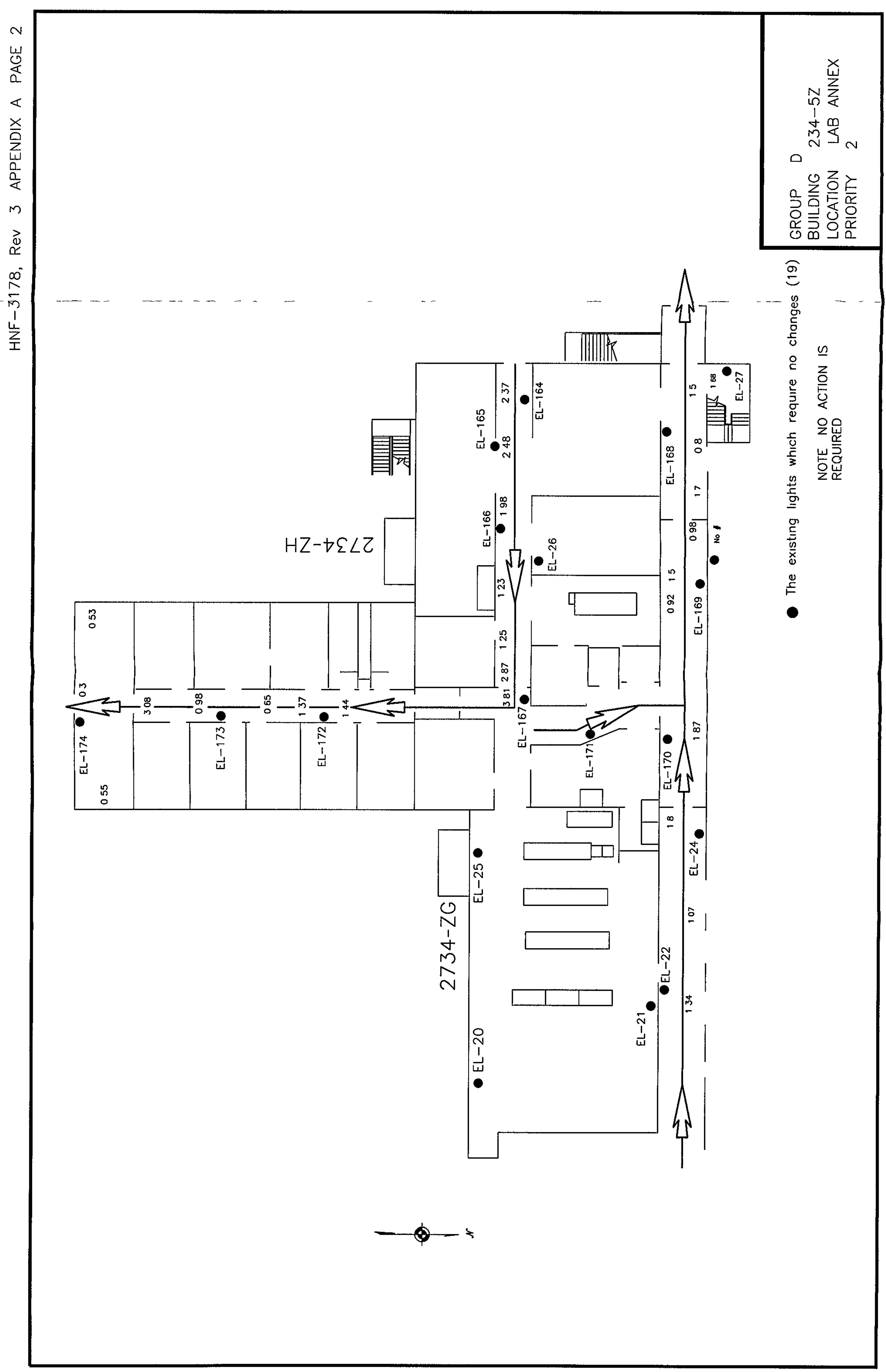




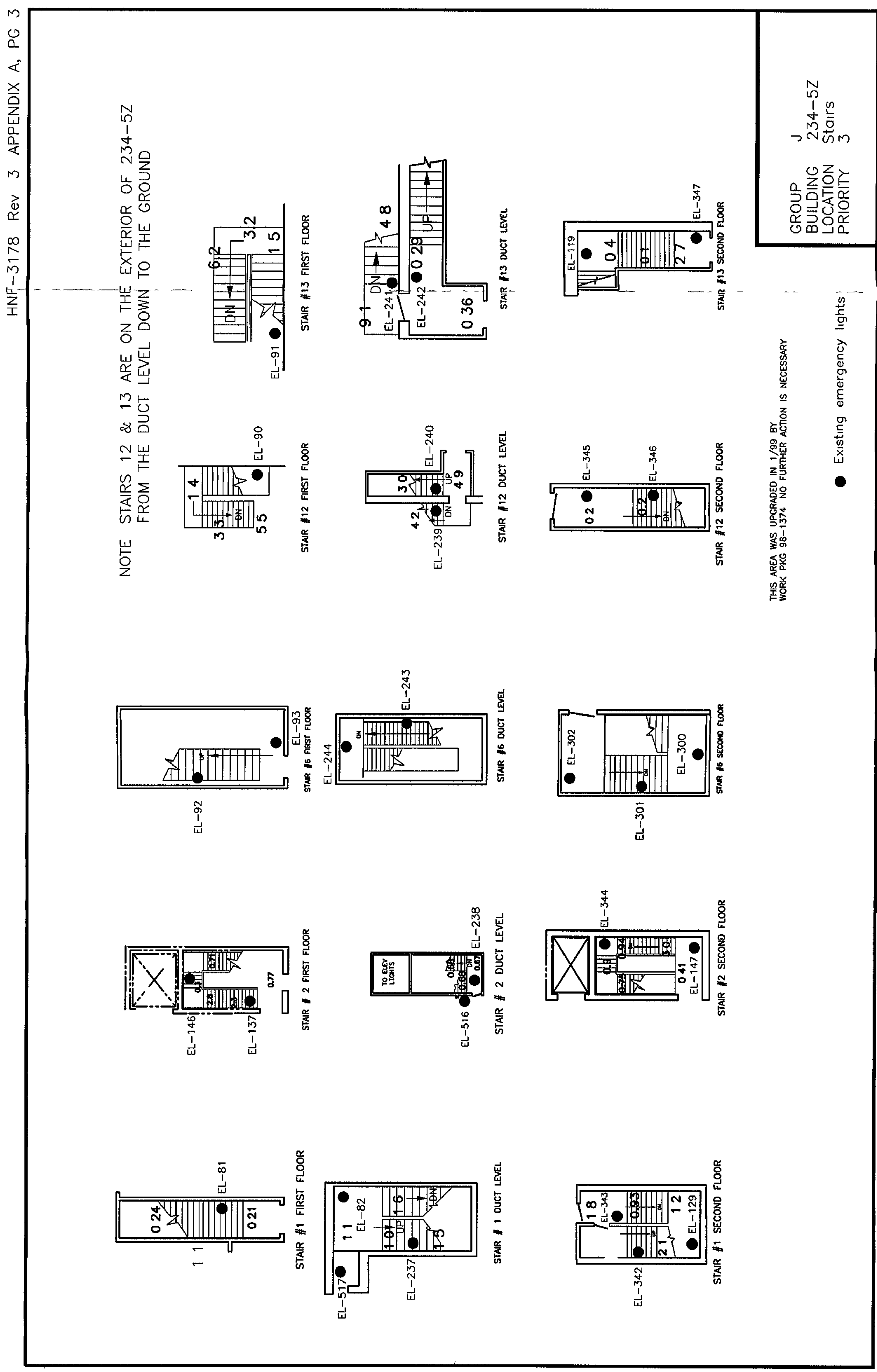




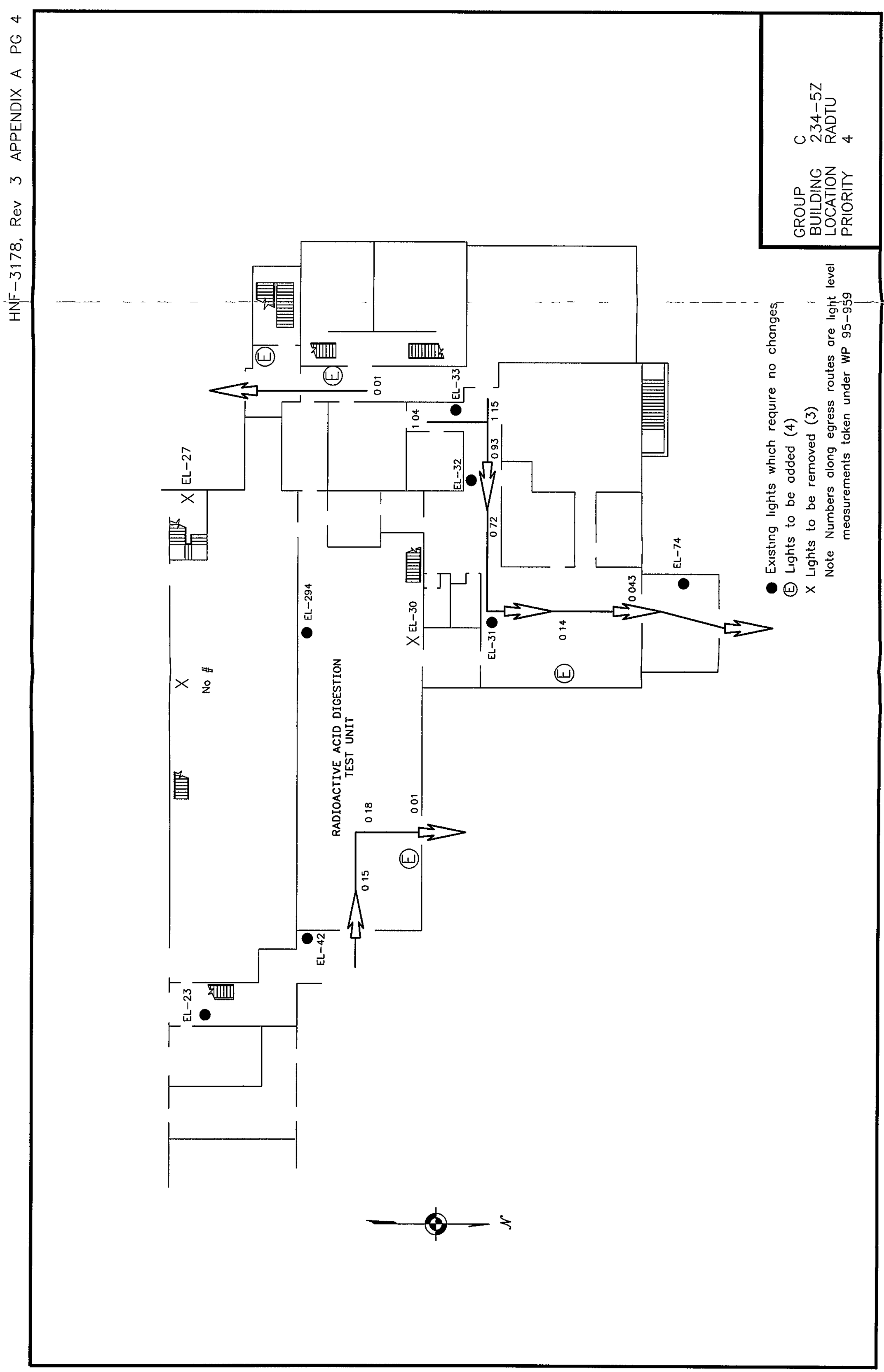




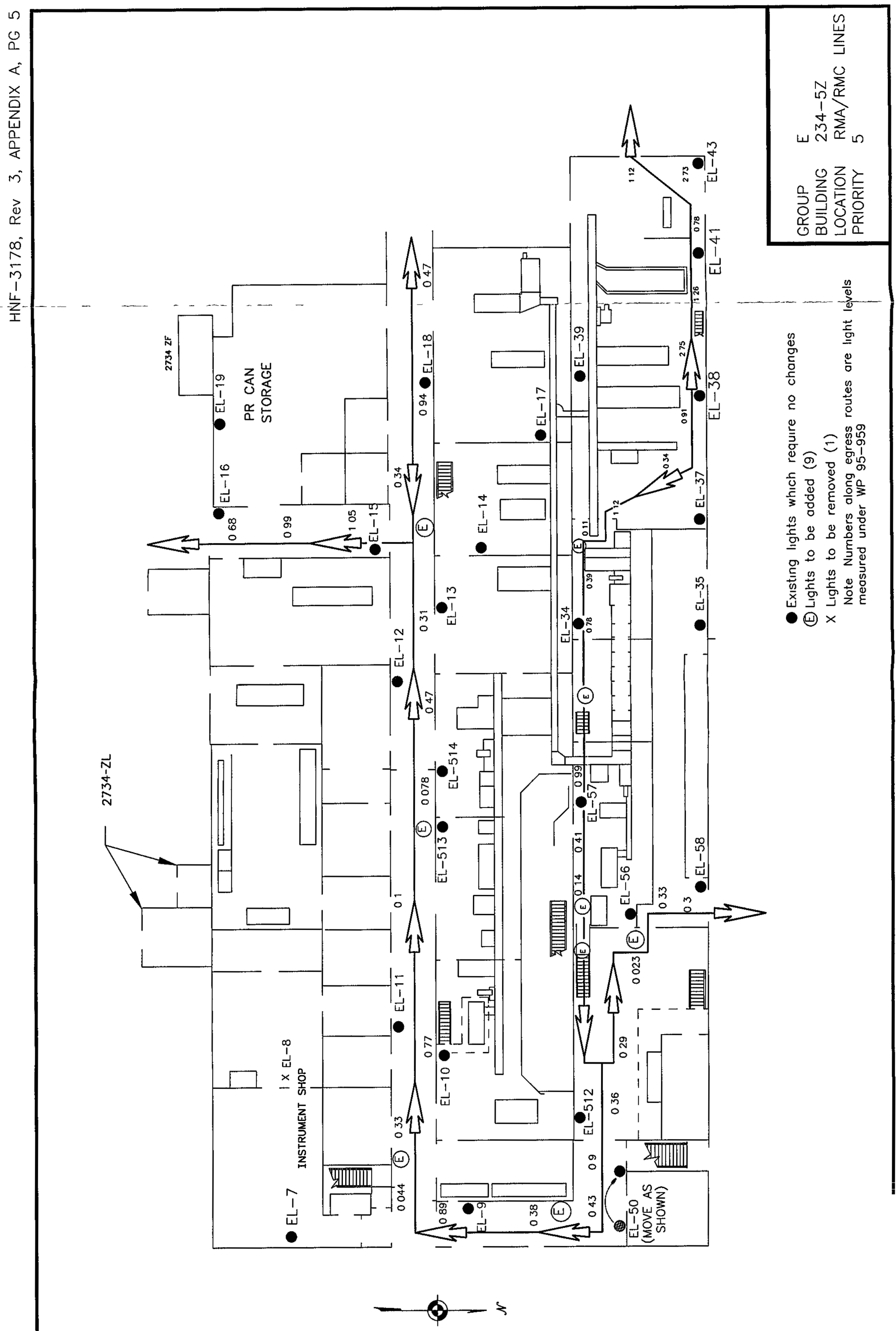




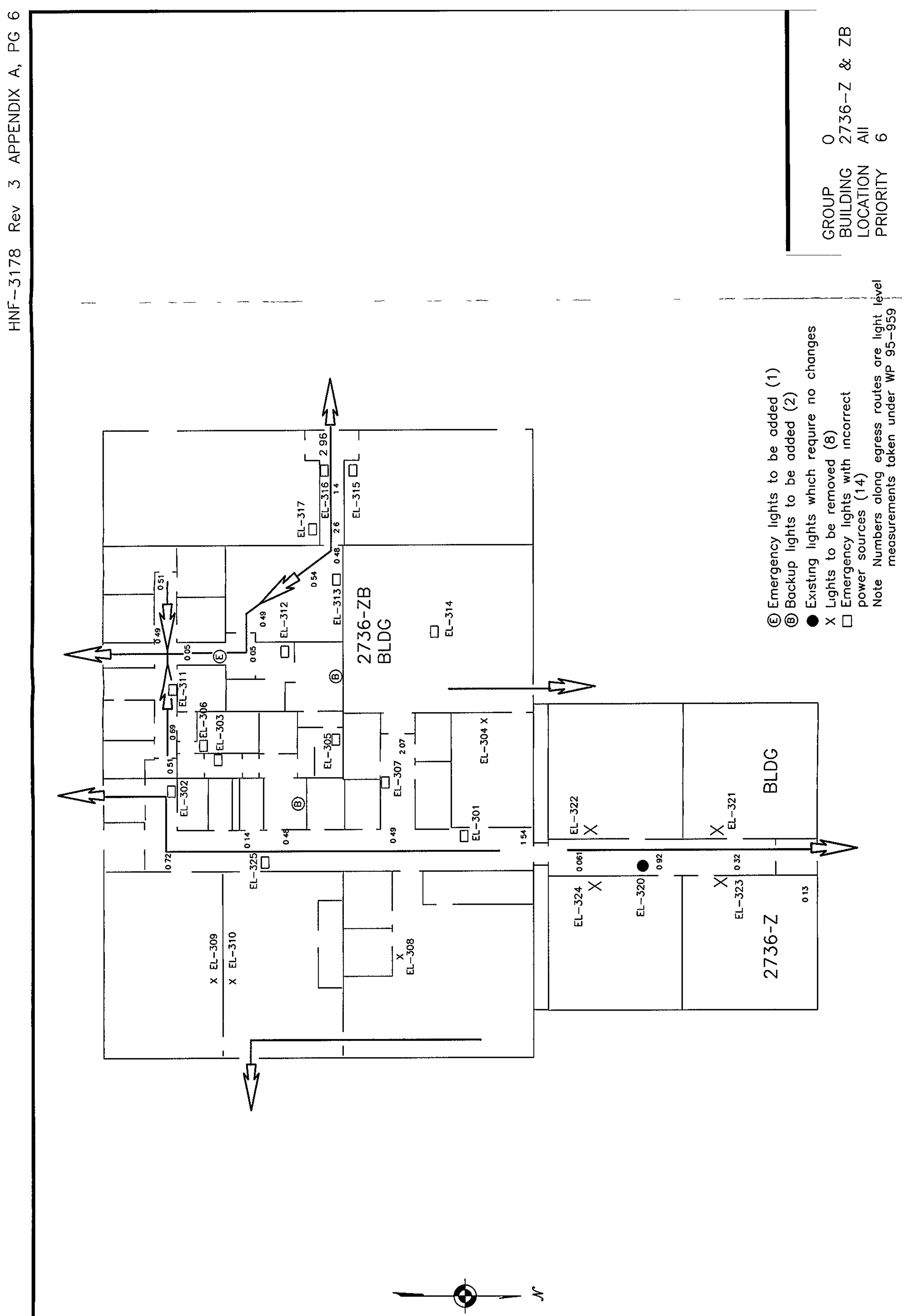




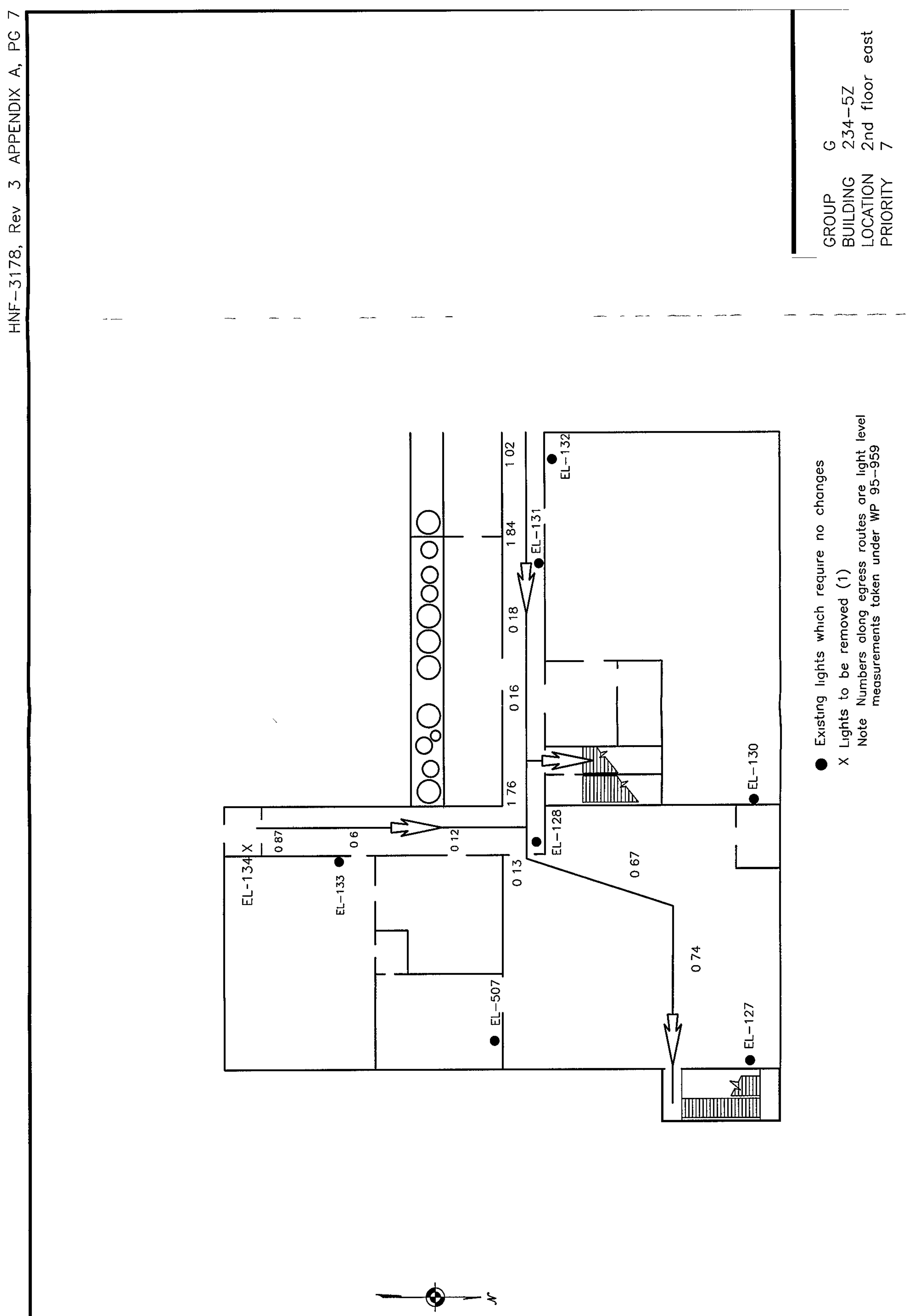




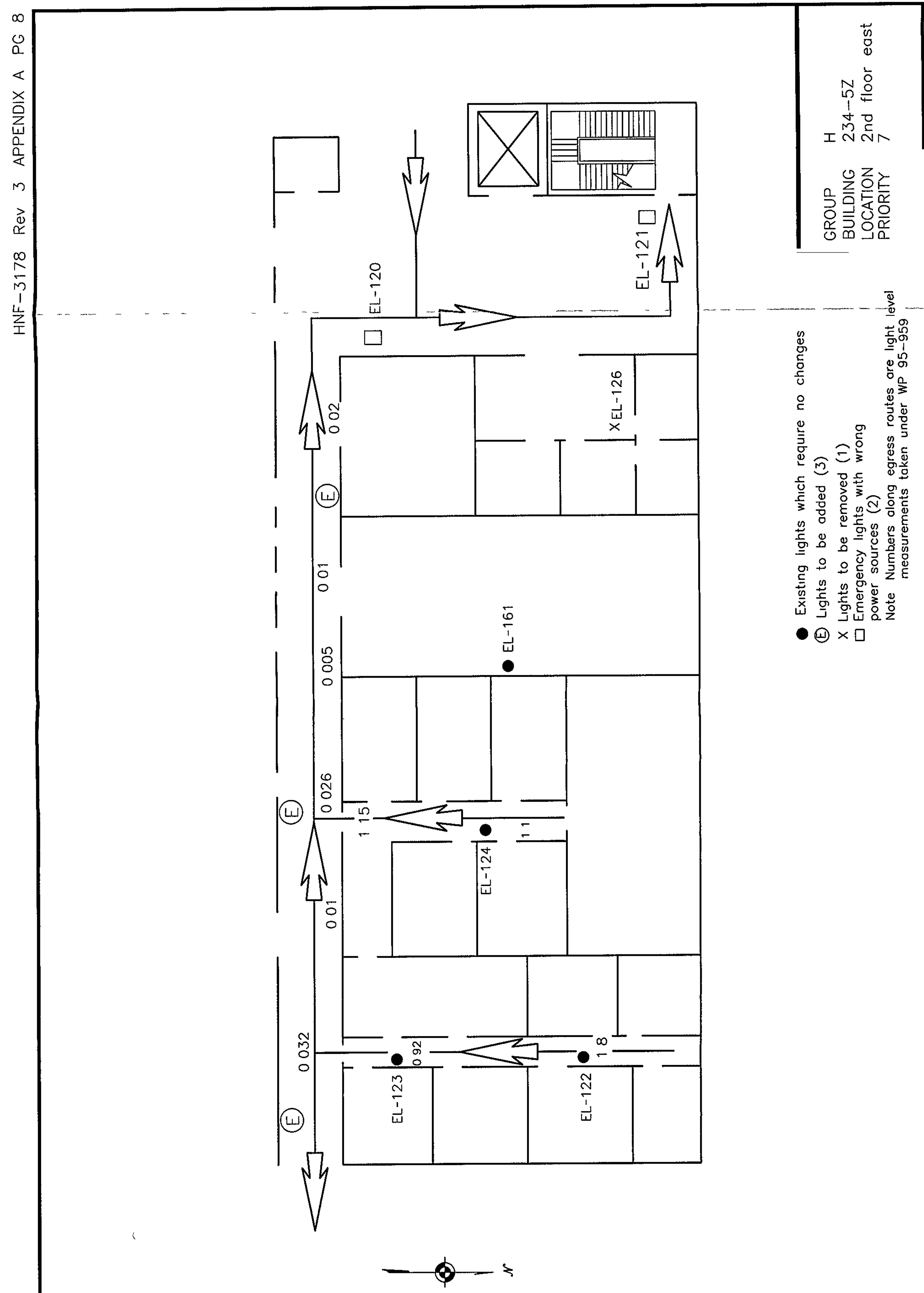




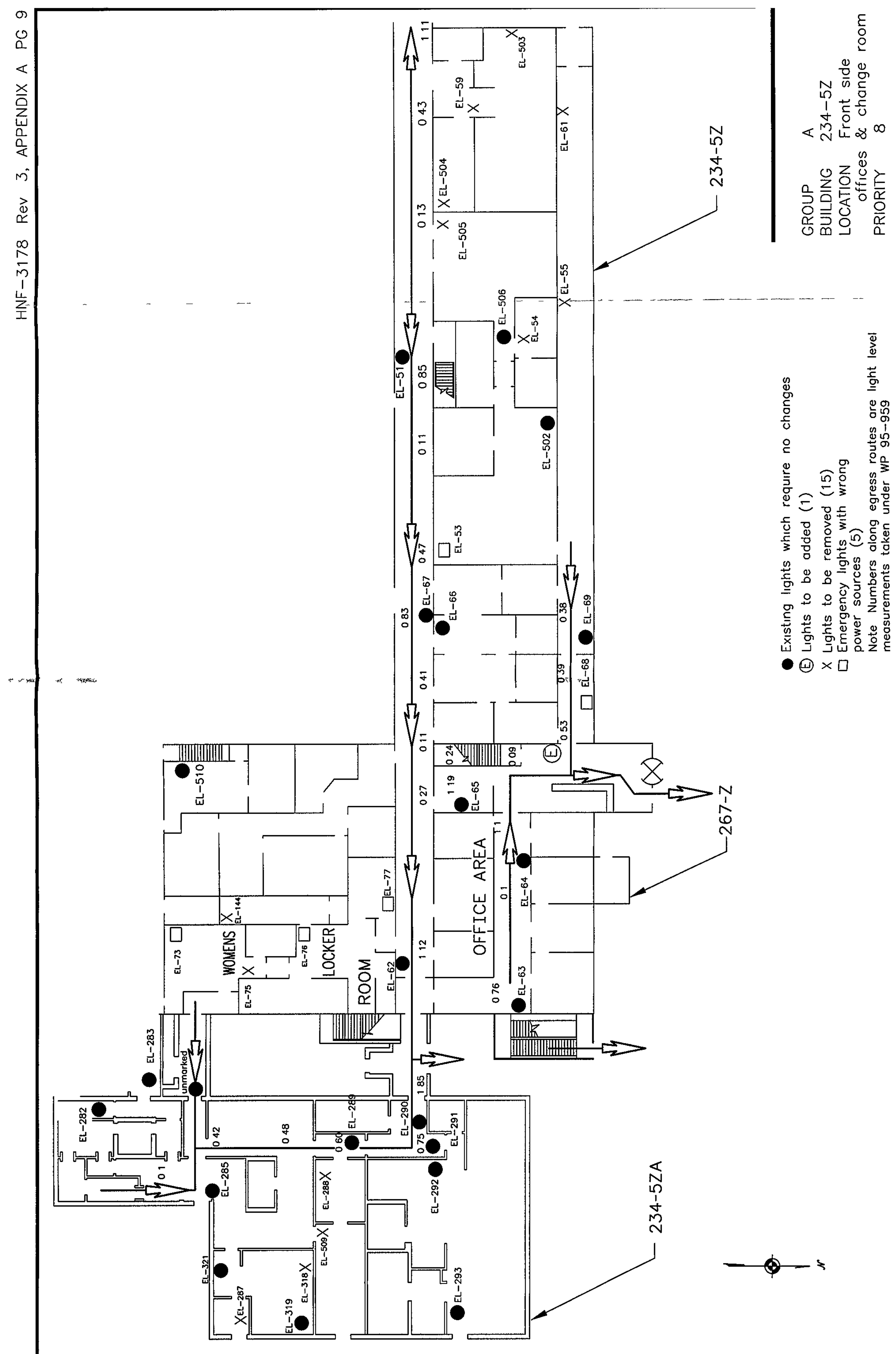




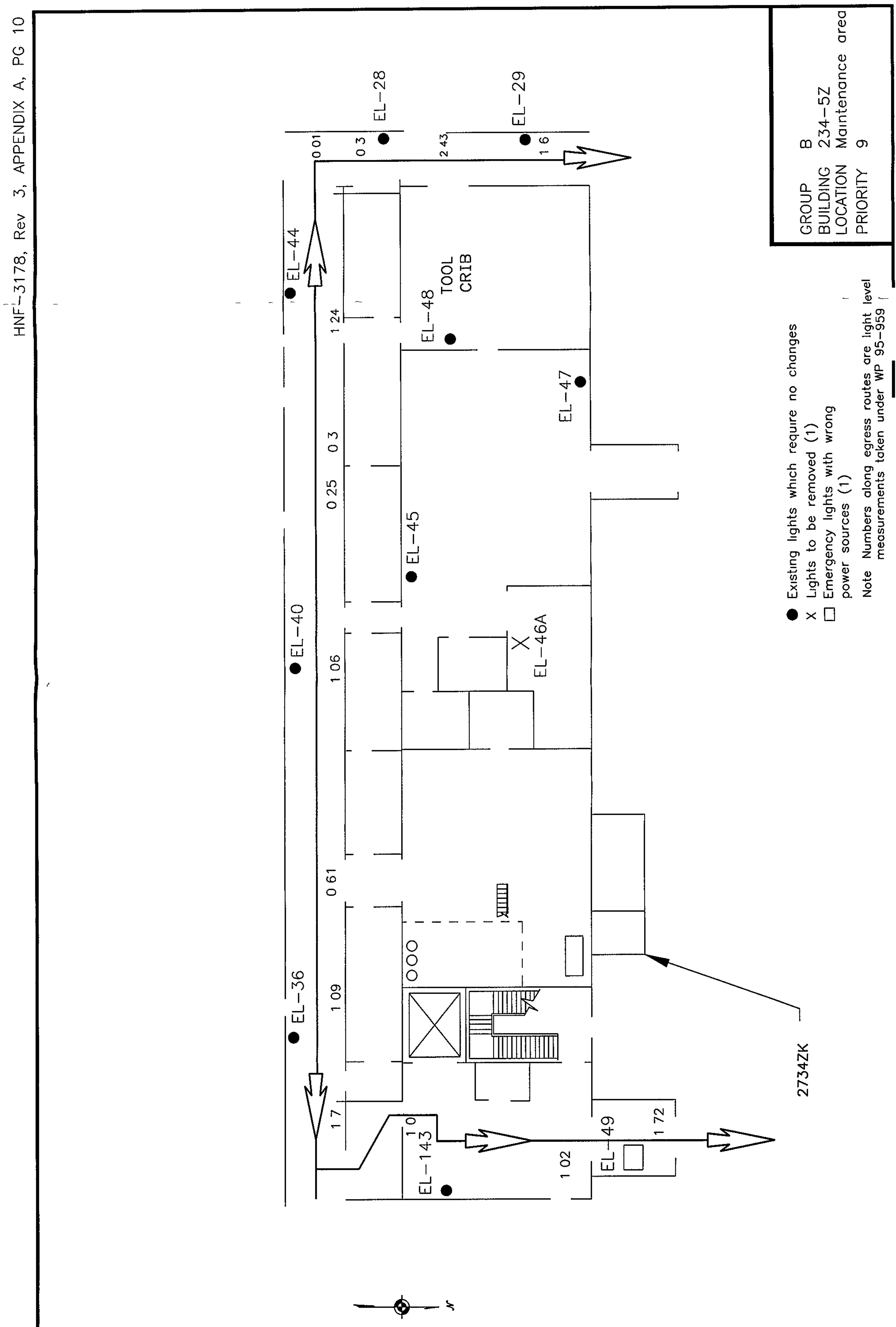




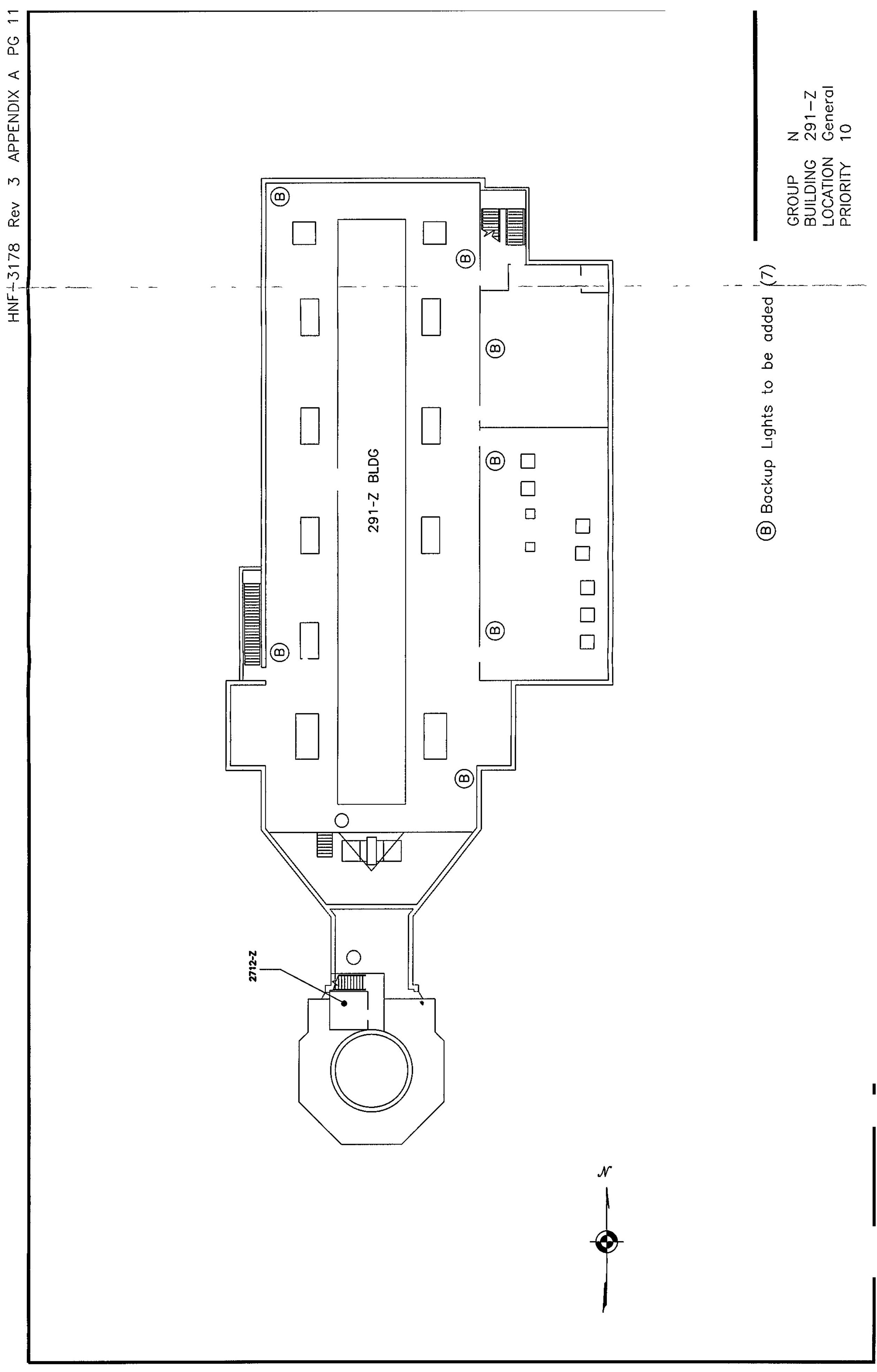



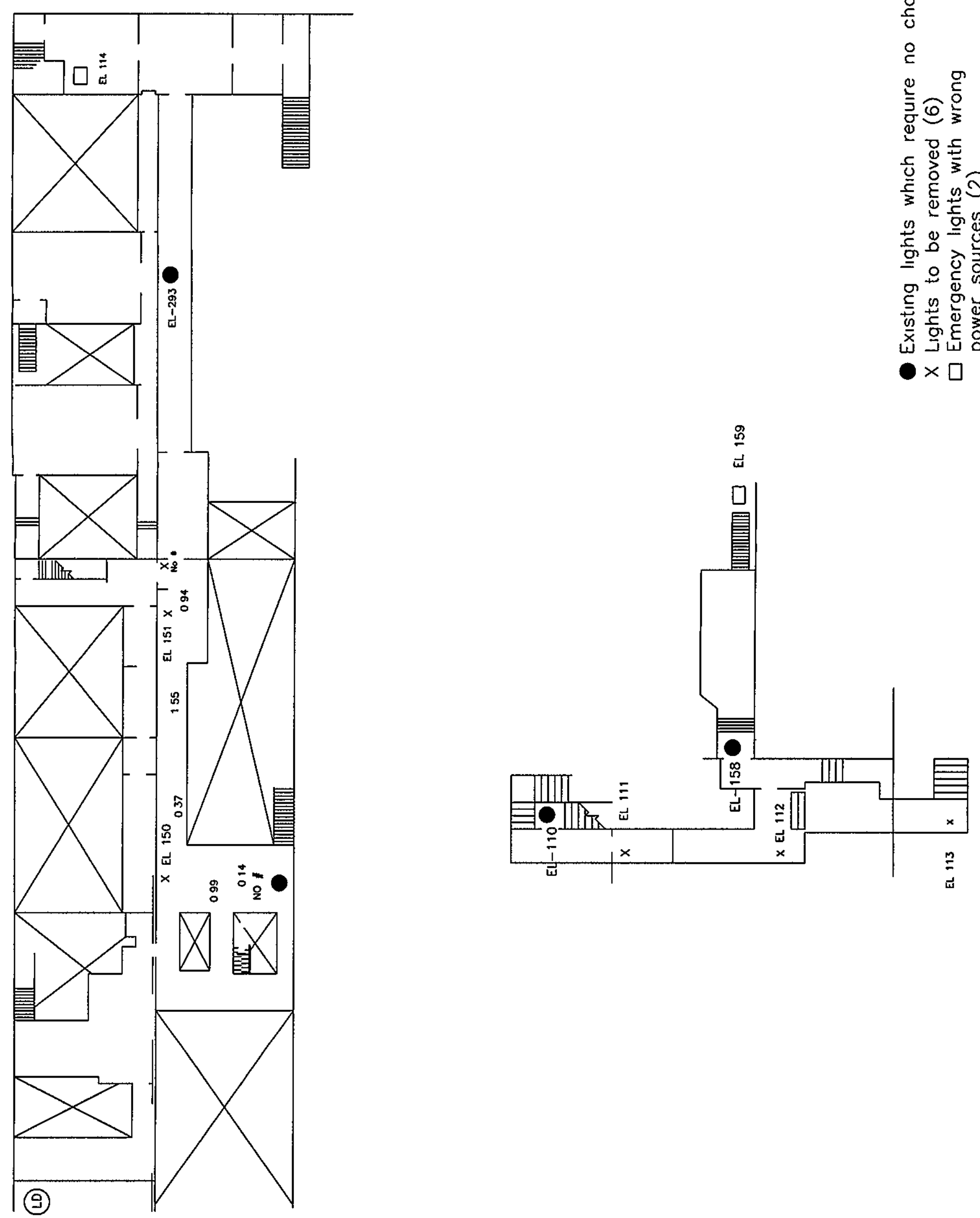


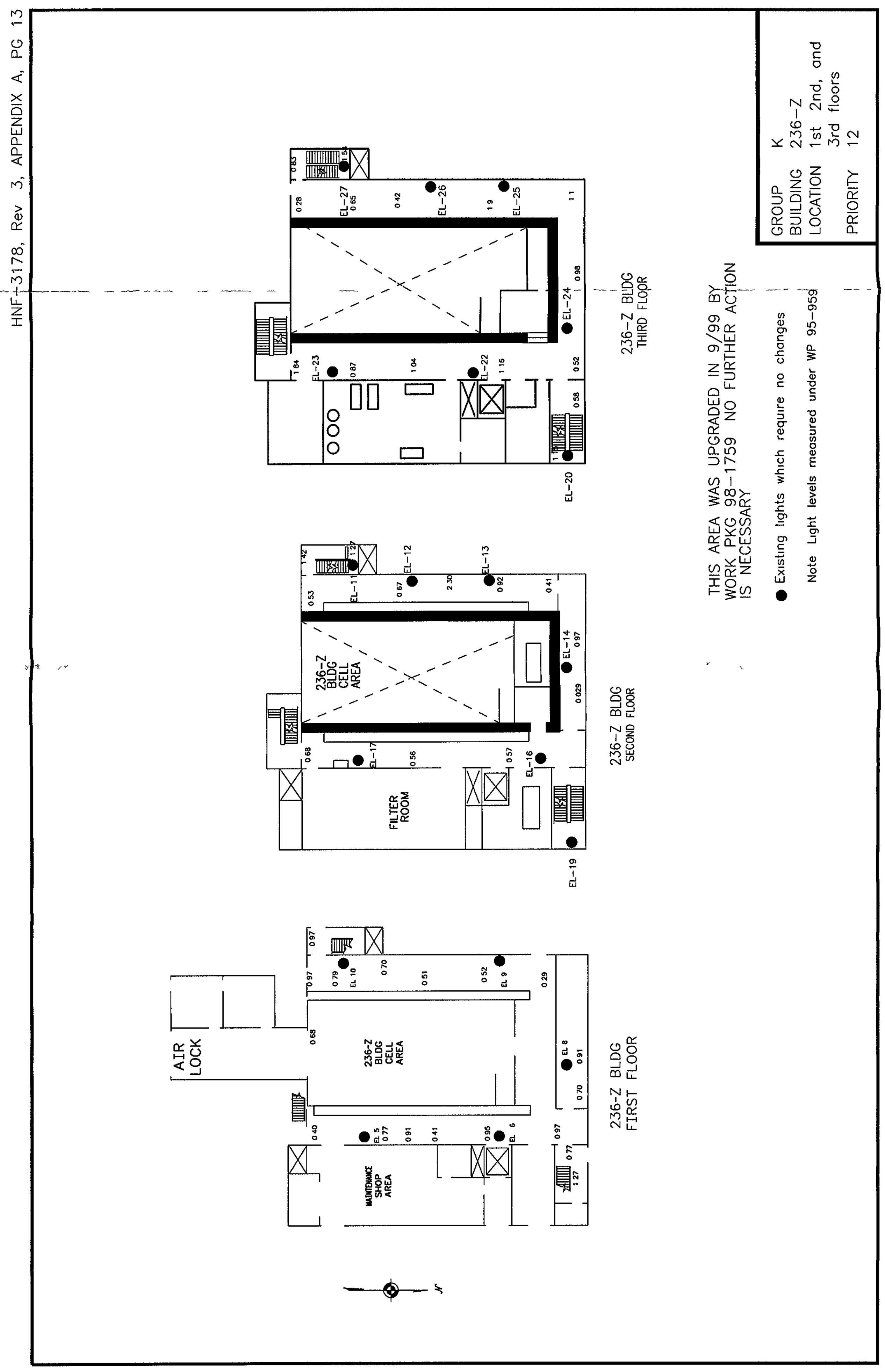




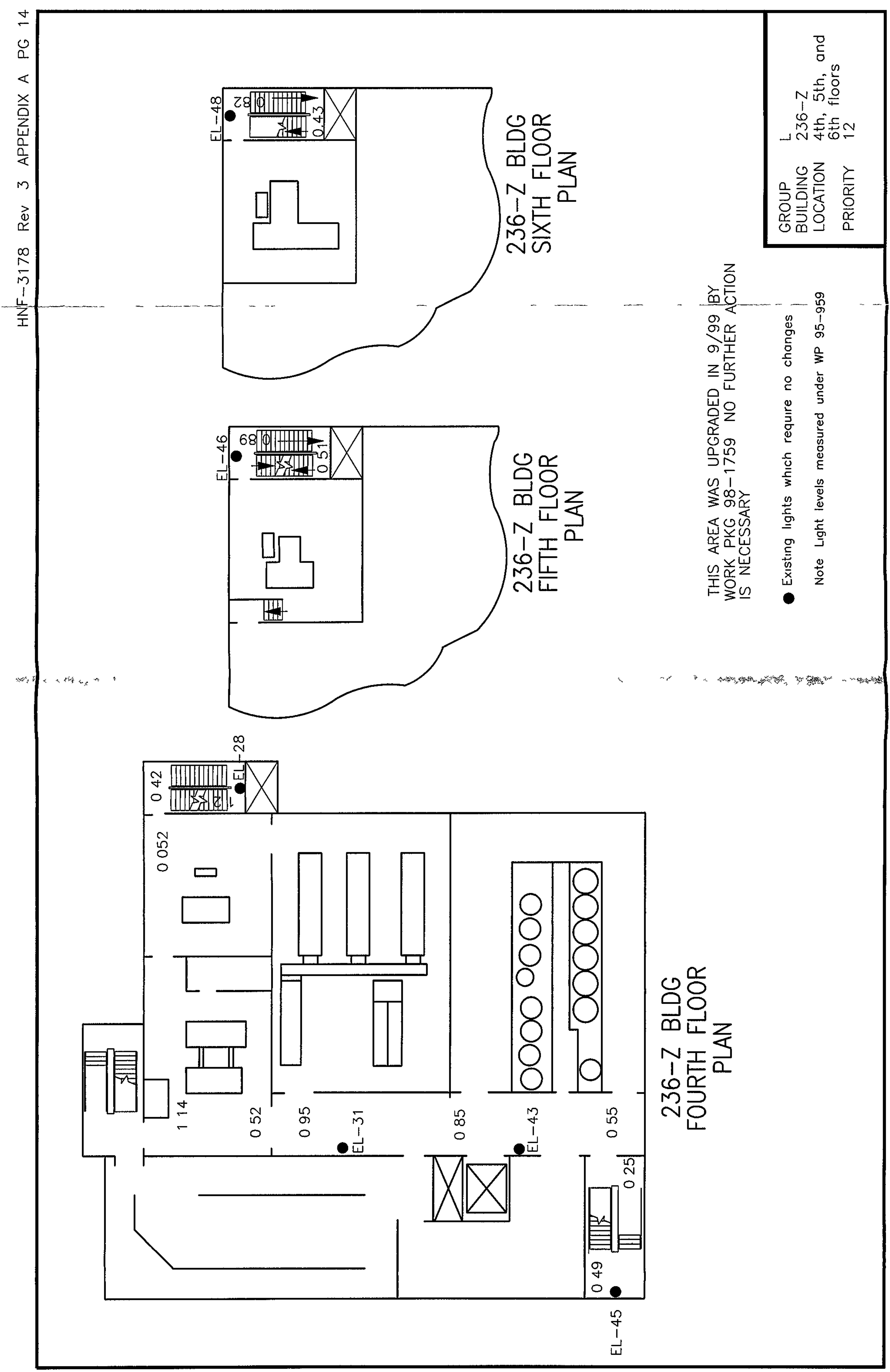




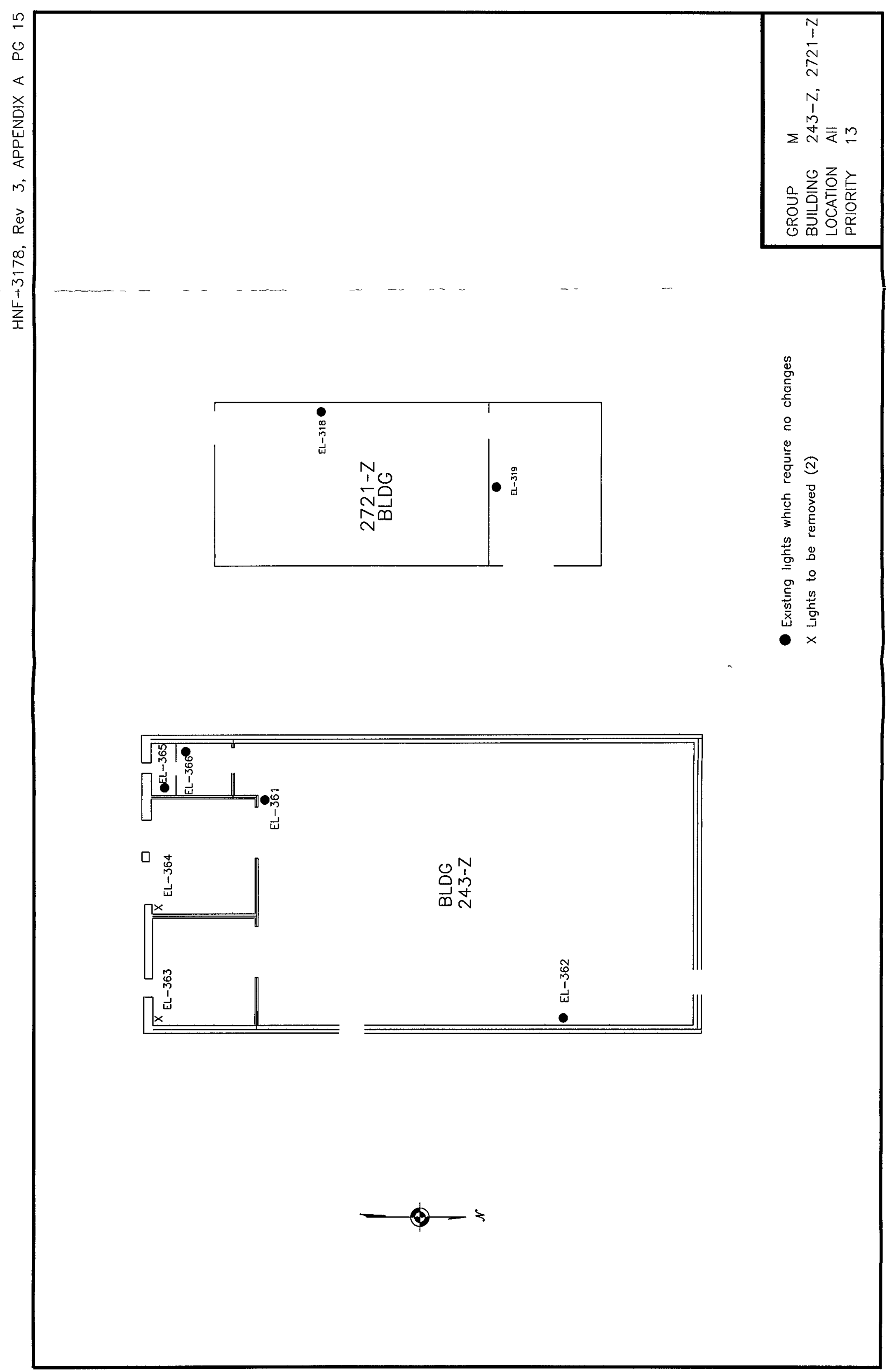




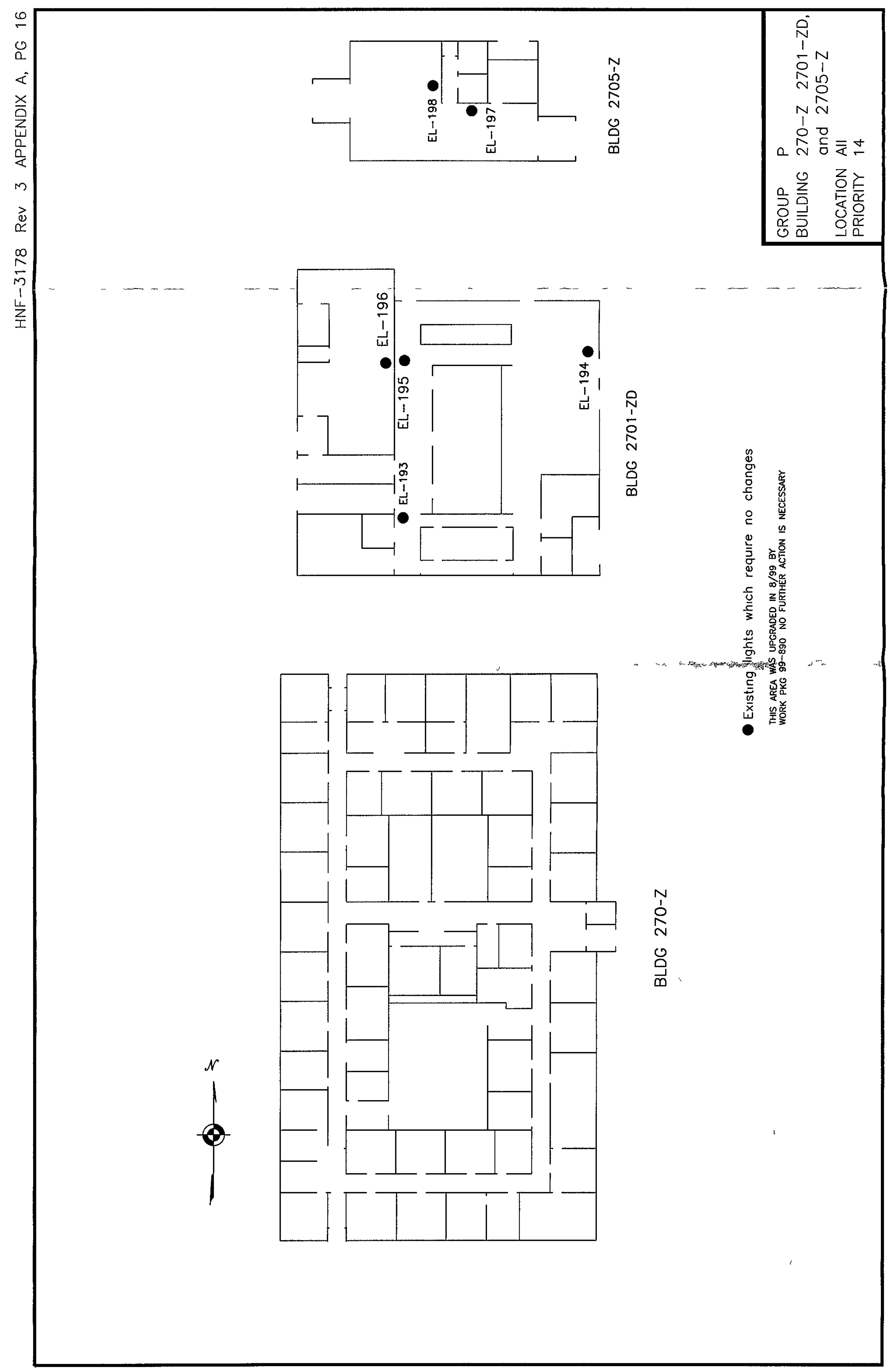




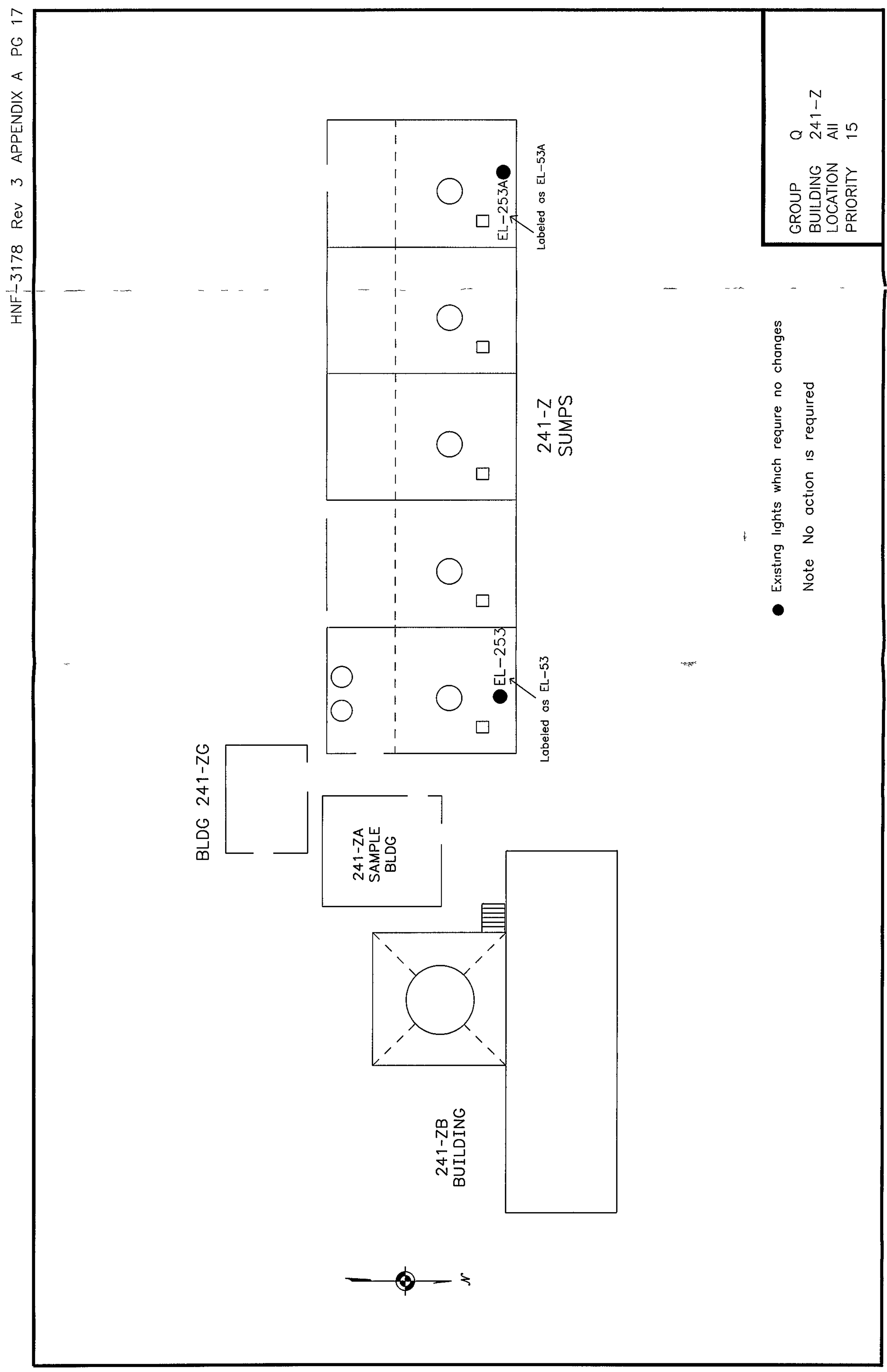




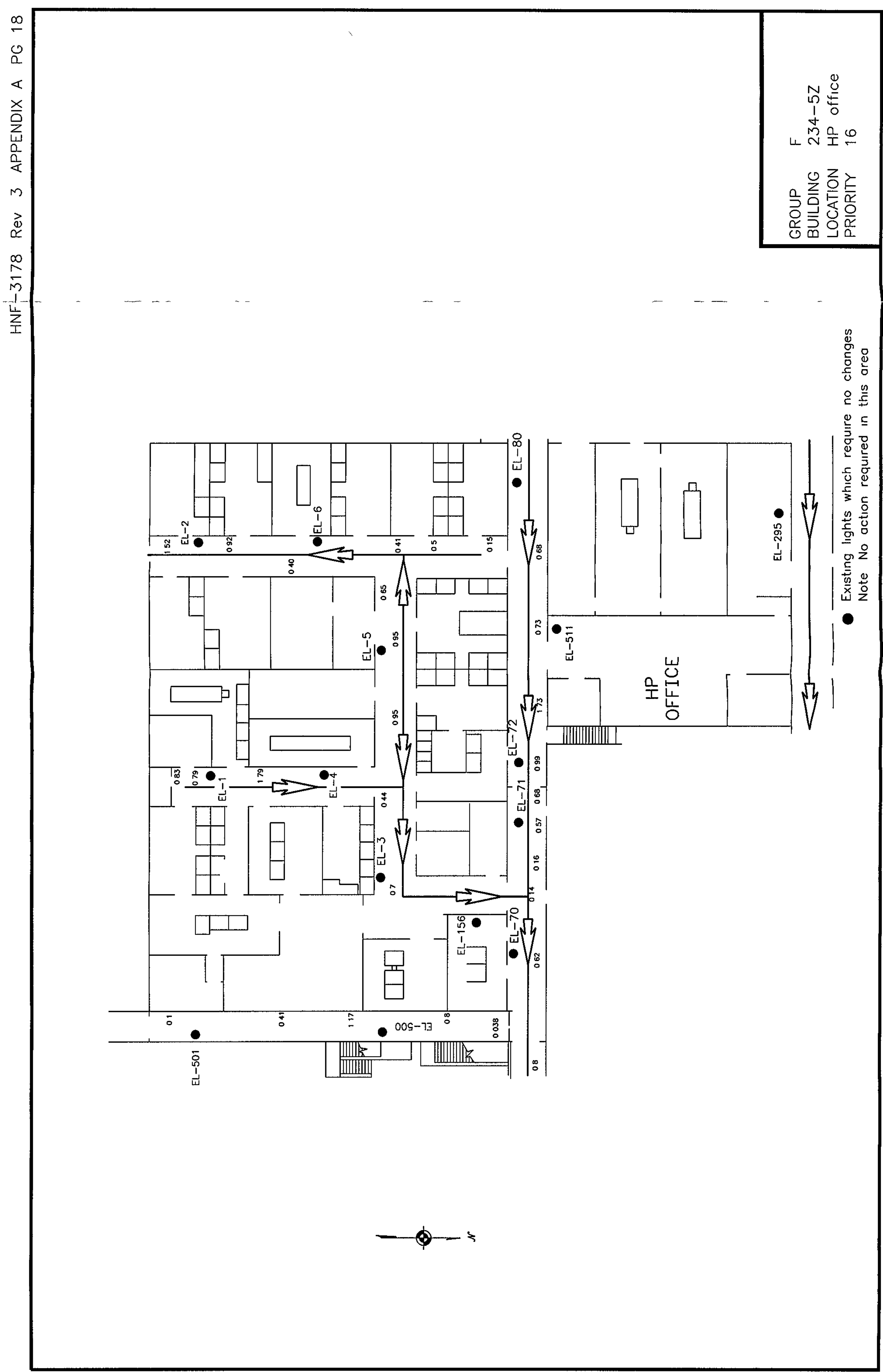

